(RESEARCH ARTICLE)

\title{
Determination of bioactive constituents of Spondias mombin leaves by GC-MS analysis
}

\author{
Olufunke Christy Akanji *
}

Department of Plant Science and Biotechnology, Adekunle Ajasin University, Akungba Akoko, Ondo-State, Nigeria.

Publication history: Received on 20 April 2020; revised on 16 June 2020; accepted on 18 June 2020

Article DOI: https://doi.org/10.30574/wjarr.2020.6.3.0111

\begin{abstract}
The therapeutic capabilities of abundant herbal products have been known. However, further researches are required to properly screen, isolate and probably characterize their various active components. In this study, an attempt was made to identify the compounds present in the ethanol and n-hexane extracts of $S$. mombin leaves using gas chromatography and mass spectrometry (GC-MS) technique. Spondias mombin leaves were collected, air dried and pulverized into powdery form and extracted with ethanol and n-hexane at room temperature. The ethanol and n-hexane extracts of $S$. mombin leaves were analyzed by GC-MS. The GC-MS analysis of the ethanol extract of $S$. mombin leaves showed twenty-five (25) compounds, while twenty-nine (29) compounds were identified in n-hexane extract of $S$. mombin leaves. However, both extracts had ten compounds in common: n-Hexadecanoic acids, Phytol, Phenol 3pentadecyl-, Phenol 3-methyl-, Phenol 2-methyl-, 2H-1-Benzopyran-6-ol, Gamma-Tocopherol, Vitamin E, Lup-20(29)en-3-one and Stigmast-4-en-3-one. The percentage proportion of these compounds differed in each extract. In view of this, the possible biological properties of these identified compounds suggested that $S$. mombin might possibly be potential therapeutic agents.
\end{abstract}

Keywords: GC-MS; Spondias mombin; Extract; Therapeutic agents.

\section{Introduction}

Traditional medicine has remained a great alternative basis of medicine worldwide, particularly in low income countries. It has been stated that $80 \%$ of the world populace (about 4 billion people) are dependent mainly on herbal therapies and traditional therapeutic practice for their well-being care (Ekor, 2014). The increasing occurrence of resistance (particularly to antibiotics), detrimental side effects, cost of accessible therapies and the well understanding of illness conditions has led to a renewed curiosity in the development of newer molecules from natural bases (Cowan, 1999). Therefore, aggressive screening of flora used in traditional medicine as well as an attempt to recognize and undertake chemical clarification of the compounds accountable for their stated activities are been undertaken by researchers (Elufioye and Berida, 2018).

Gas Chromatography Mass Spectrometry (GC-MS) is one of the compatible techniques advantageous in recognizing the bioactive components of long chain, alcohols, branched chain hydrocarbons, esters, acids, etc present in crude plant materials (Sathiyabalan et al., 2014). Gas chromatography (GC) is broadly used for compound analysis, drug screening and assessment resulting from environmental pollution. Mass spectrometry (MS) measures the mass-to-charge ratio of ions of analysts and is a plot of strength as a function of mass-to-charge ratio (Kim et al., 2005; Shah et al., 2019). Relying on the database of National Institute of Standards and Technology Chemistry Web Book (2019) for diverse compounds, researchers can thus recognize and quantify these potential compounds and components.

Amongst numerous known therapeutic plants is Spondias mombin. Spondias mombin L. (Family-Anacardiaceae) also recognized as Hog plum, is a plant that grows in nearly every part of the world. It is a deciduous tree that produces many

\footnotetext{
* Corresponding author: Olufunke Christy Akanji; Phone: +2347032462092; Email:funkebb@yahoo.com
} 
fruits which is about $20 \mathrm{~m}$ tall and it grows in the rain forest and the coastal part of Africa. It is recognized locally as "iyawe" and "iyeye" by the Hausa and Yoruba people of Nigeria respectively (Dharmananda, 2003). Tradomedicine physicians across Africa use all parts of the plant for therapeutic purposes. The fruits' decoction is drunk as a febrifuge and diuretic, while the decoction of the leaves and stem-bark are used as an emetic, dysentery and anti-diarrhea (Osuntokun et al., 2018). Spondias mombin is a good recipe for the treatment of gonorrhea and leucorrhea as well as for haemorrhoids (Li et al., 2003). A tea of the leaves and flowers of S. mombin is taken to relieve stomach ache, biliousness, cystitis, urethritis, throat and eye inflammations. Herbalists in Southwest Nigeria use the plant in the treatment of diabetics, psychiatric disorders, typhoid, nervous disorders and tuberculosis (Newman et al., 2008). The extract of the powder of the dried leaves and fresh crushed leaves are used for healing inflammation, wounds, varicose ulcers, burn and frost-bite in herbal medicine (Shaarawy et al., 2009). The bark, fruits and leaves of $S$. mombin are said to be rich in antioxidants and other valuable phytochemicals (Igwe et al., 2011; Omoregie and Oikeh, 2015). However, much work has not been done on the identification of the compounds accountable for these stated activities. Using GC-MS, we aimed to identify the compounds present in the ethanol and n-hexane extracts of $S$. mombin leaves.

\section{Materials and methods}

\subsection{Collection of Plant Sample}

Spondias mombin leaves were obtained from the Faculty of Pharmacy's premises, University of Benin, Benin City, Edo State, Nigeria and authenticated at the Department of Plant Biology and Biotechnology with voucher number UBH-S345. The plant was air dried under room temperature and pulverized into powdery form which was kept in an air-tight container ready for the analysis.

\subsection{Plant extraction}

Cold extraction method was used in this study, by dissolving the pulverized plant material in ethanol and n-hexane as solvents. The filtrate for each extraction was combined, and evaporated to dryness at room temperature.

\subsection{Gas Chromatography - Mass Spectrometry (GC-MS)}

GC-MS analysis of the ethanol and n-hexane extracts of $S$. mombin leaves were performed using Hewlett-Packard (HP) 6890 series (Agilent) Gas Chromatography System, interfaced to HP 5973 series (Agilent) mass spectrometer, equipped with an autosampler and a single capillary injector. TR-FAME (Thermo $260 \quad$ M142P) (70 \% cyanopropylpolysilphenylenesiloxane) capillary GC column (30 m x $0.25 \mathrm{~mm}$, i.d., x $0.25 \mu \mathrm{m}$ film thickness) was also used. This was done by dissolving the sample in the organic solvent till it dissolved completely. GC condition was maintained at $100-280{ }^{\circ} \mathrm{C}$ as $5{ }^{\circ} \mathrm{C} / \mathrm{min} .2 \mu \mathrm{l}$ of sample was injected into the column. The helium gas was allowed to move at $1 \mathrm{ml} / \mathrm{min}$ through the column and the compound split in the ratio of 1:10. After the program, mass spectrometer scanned the compounds separated and each peak area was measured to find the compounds present at the area. The results were represented as chromatogram graph in the GC-MS.

\section{Results}

The GC analysis and mass spectral data of the ethanol and n-hexane extracts of $S$. mombin leaves showing compound name, retention time, peak area (\%), molecular weight $(\mathrm{g} / \mathrm{mol})$, structural formula, compound nature and structure of compound is presented in Tables 1 and 2. Twenty five (25) compounds were identified in the ethanol extract (Table 1), while twenty-nine (29) compounds were detected in the n-hexane extract of the $S$. mombin leaves (Table 2). Figures 1 and 2 depict the chromatograms of ethanol and n-hexane extracts of $S$. mombin leaves respectively with their peak areas. In ethanol extract, phenol, 2-methyl- gave the highest peak at 21.918 retention time (Figure 1) while phenol, 3-methylgave the highest peak at 21.941 retention time in n-hexane extract (Figure 2). 
Table 1 Compounds Identified in Ethanol Extract of Spondias mombin Leaves by Gas Chromatography Mass Spectrometry (GC-MS) Method

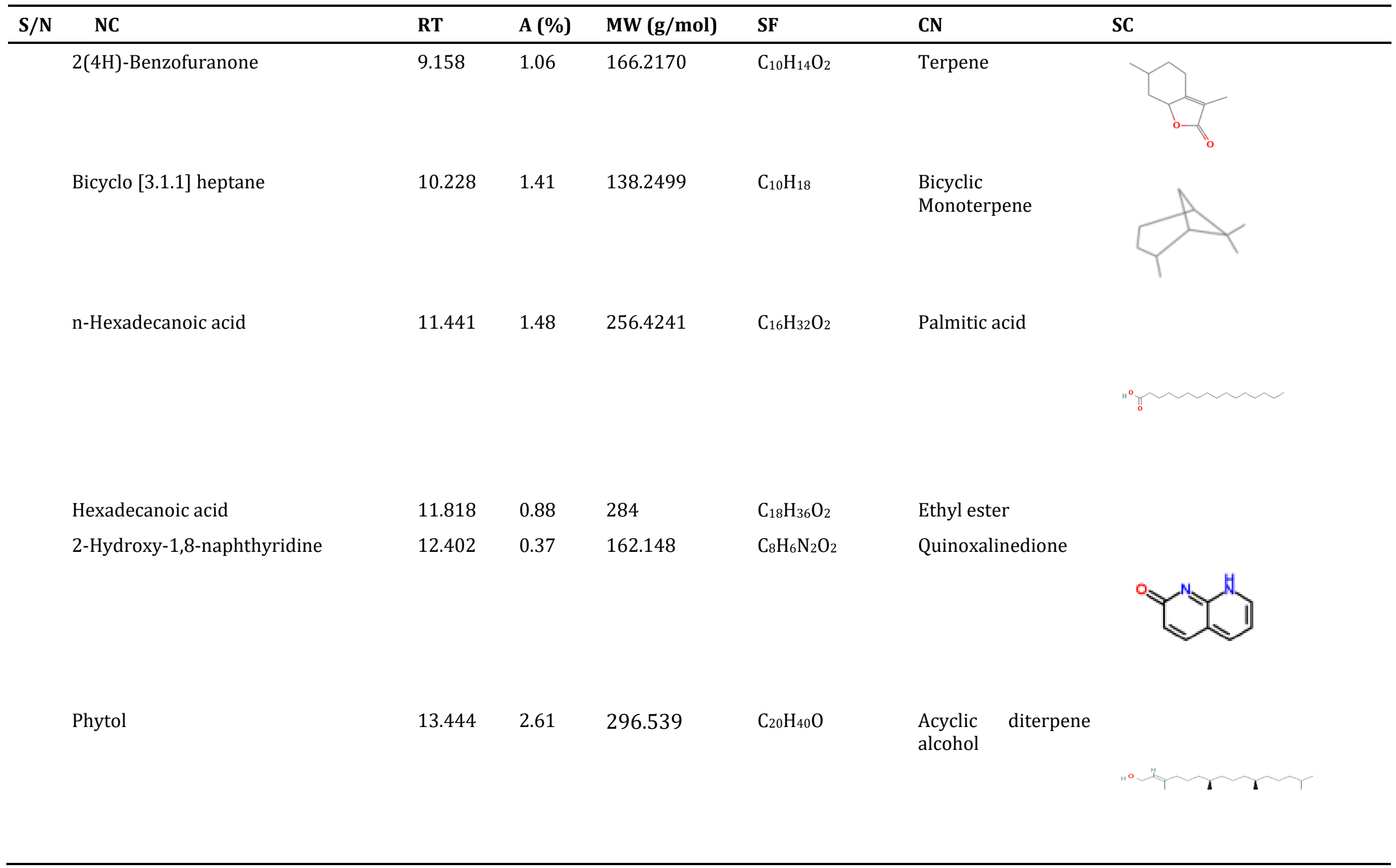


Akanji/ World Journal of Advanced Research and Reviews, 2020, 06(03), 149-165

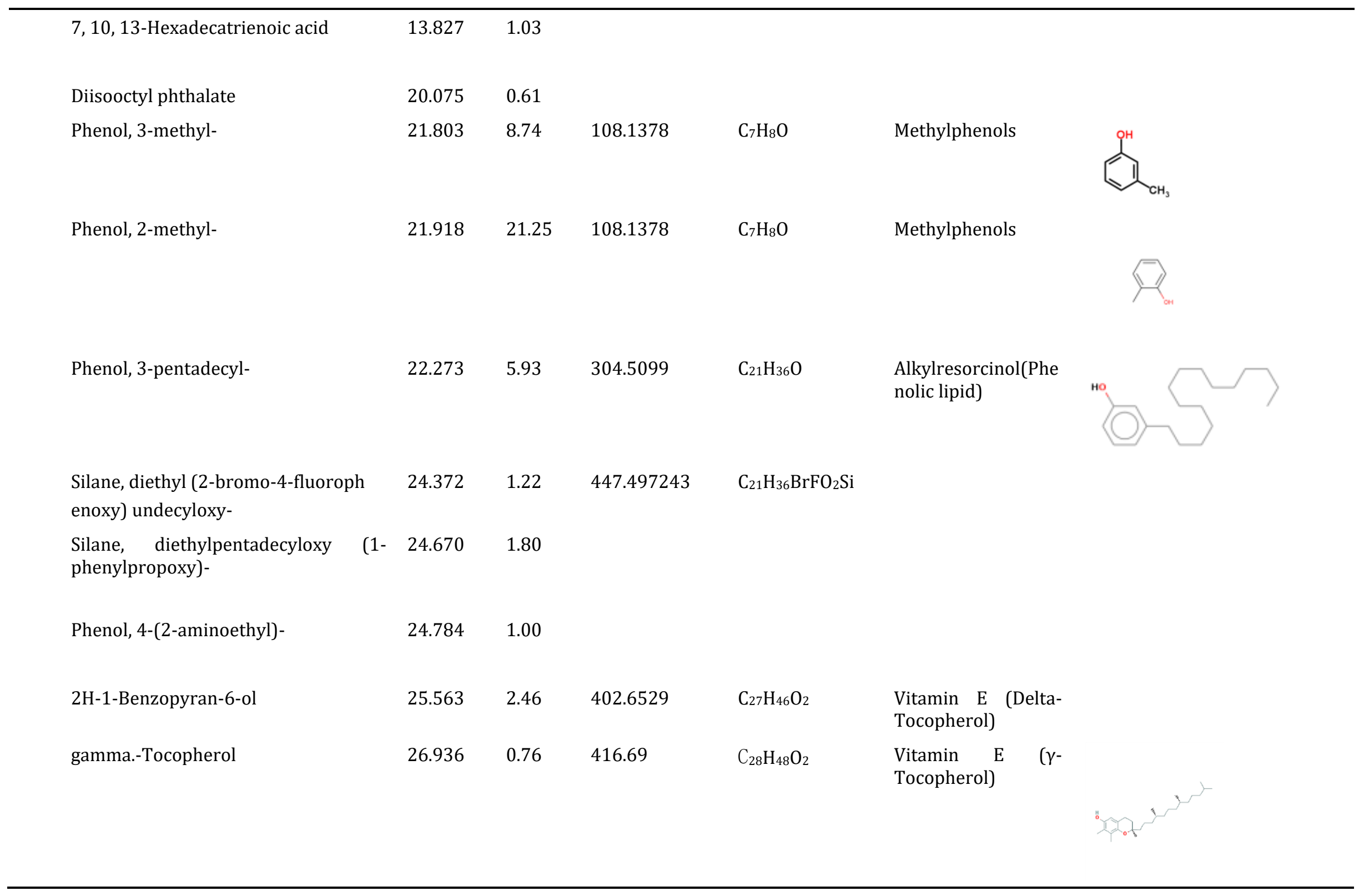


Octasiloxane, $1,1,3,3,5,5,7,7,9,9, \quad 27.840 \quad 0.54$

$11,11,13,13,15,15$-hexadecamethyl

Vitamin E

.gamma.-Sitosterol

Lup-20(29)-en-3-one

Alpha-Amyrin

27.966

1.62

28.916

1.93

30.106

30.810

7.14
430.717

207.276

$\mathrm{C}_{15} \mathrm{H}_{13} \mathrm{~N}$

16.16

414.718

414.718

$\mathrm{C}_{29} \mathrm{H}_{50} \mathrm{O}$

$\mathrm{C}_{29} \mathrm{H}_{50} \mathrm{O}$

424.713

$\mathrm{C}_{30} \mathrm{H}_{48} \mathrm{O}$

Triterpe

noid

phytosterol

Triterpene

Vitamin E (alphatocopherol)
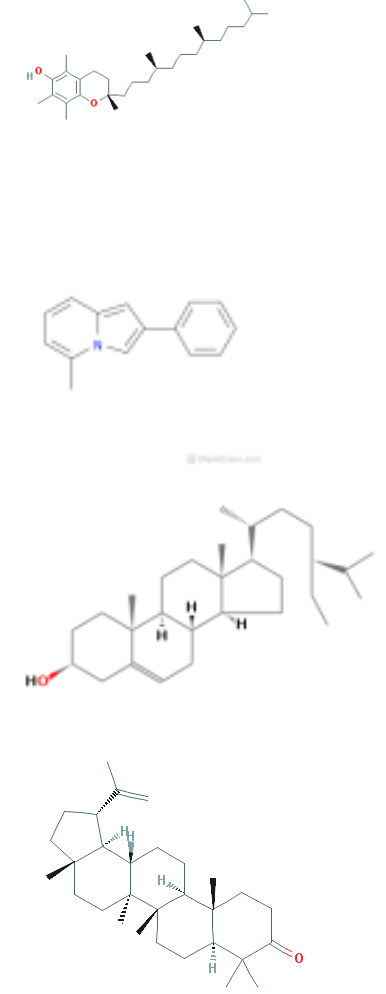

$\begin{array}{lllll}31.124 & 7.07 & 426.729 & \mathrm{C}_{30} \mathrm{H}_{50} \mathrm{O} & \text { Triterpene }\end{array}$ 


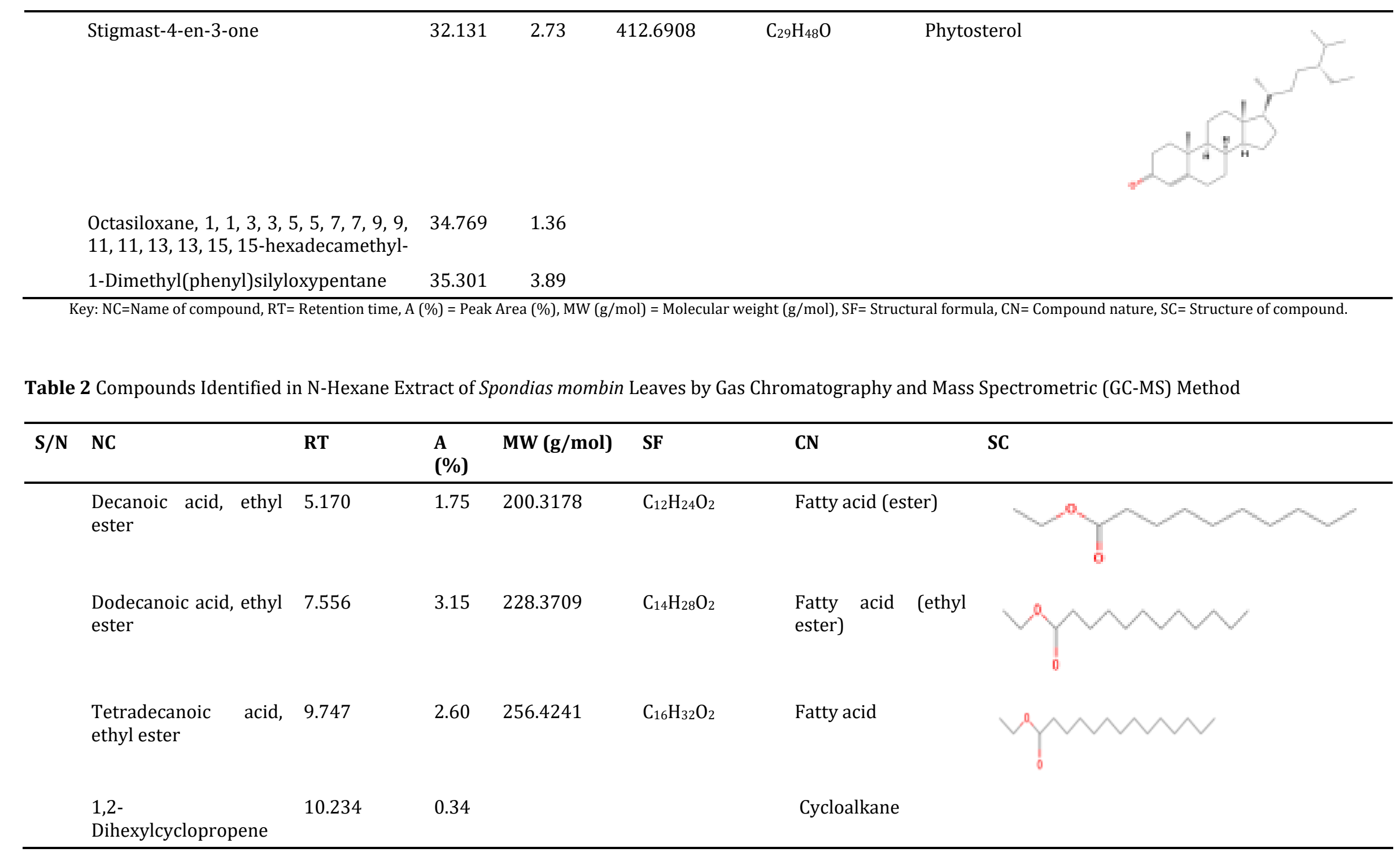


Akanji/ World Journal of Advanced Research and Reviews, 2020, 06(03), 149-165

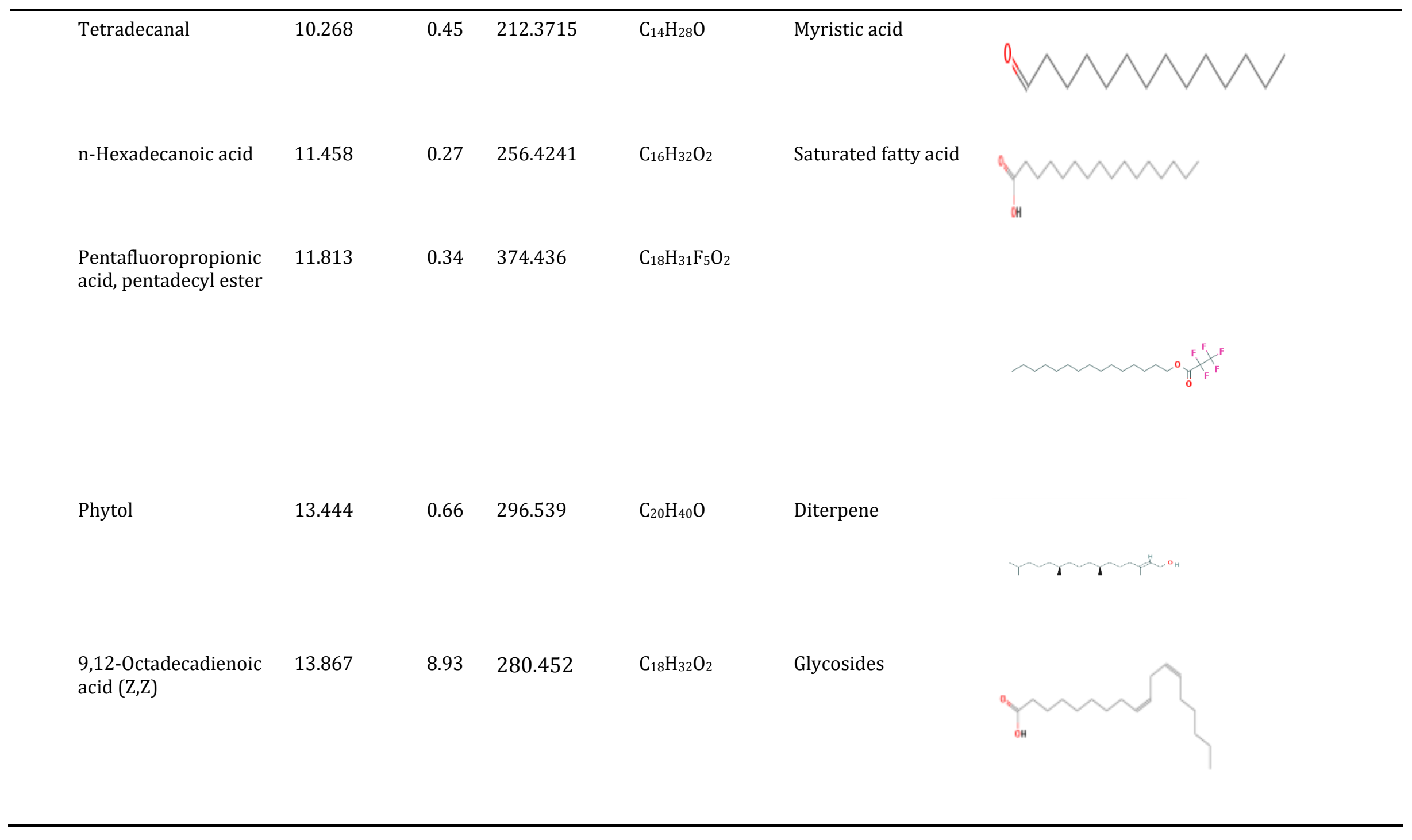


Akanji/ World Journal of Advanced Research and Reviews, 2020, 06(03), 149-165

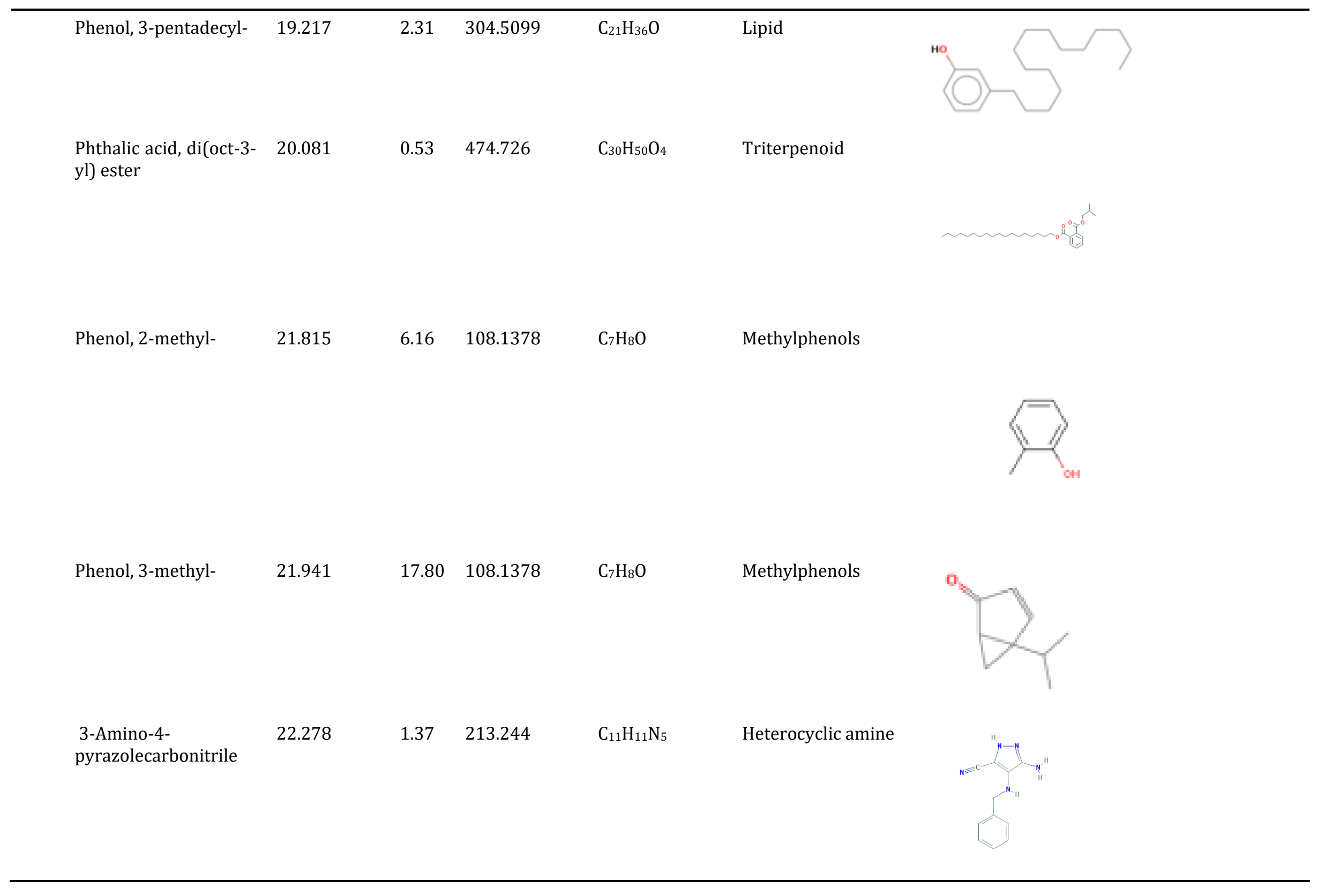


Akanji/ World Journal of Advanced Research and Reviews, 2020, 06(03), 149-165

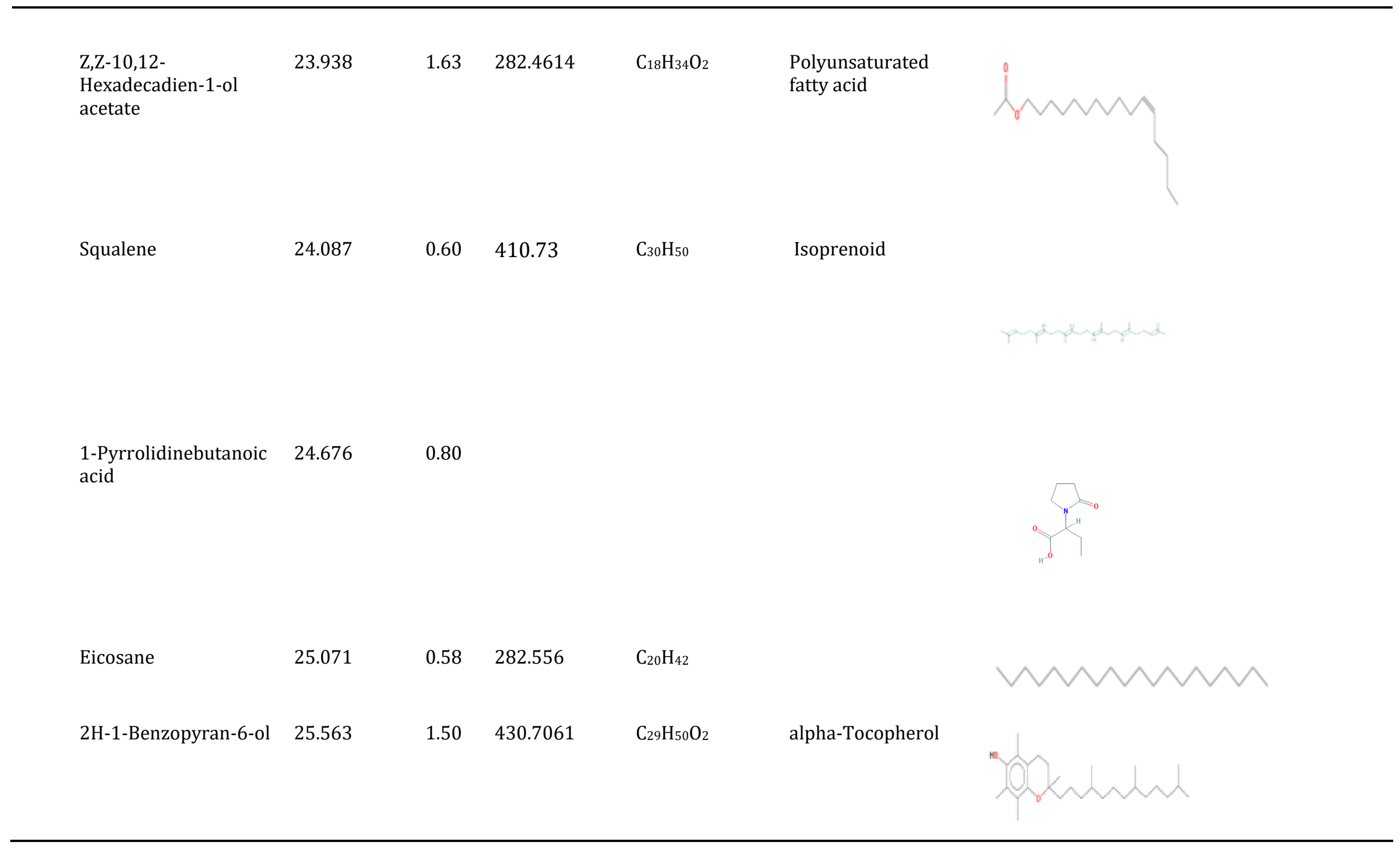


Akanji/ World Journal of Advanced Research and Reviews, 2020, 06(03), 149-165

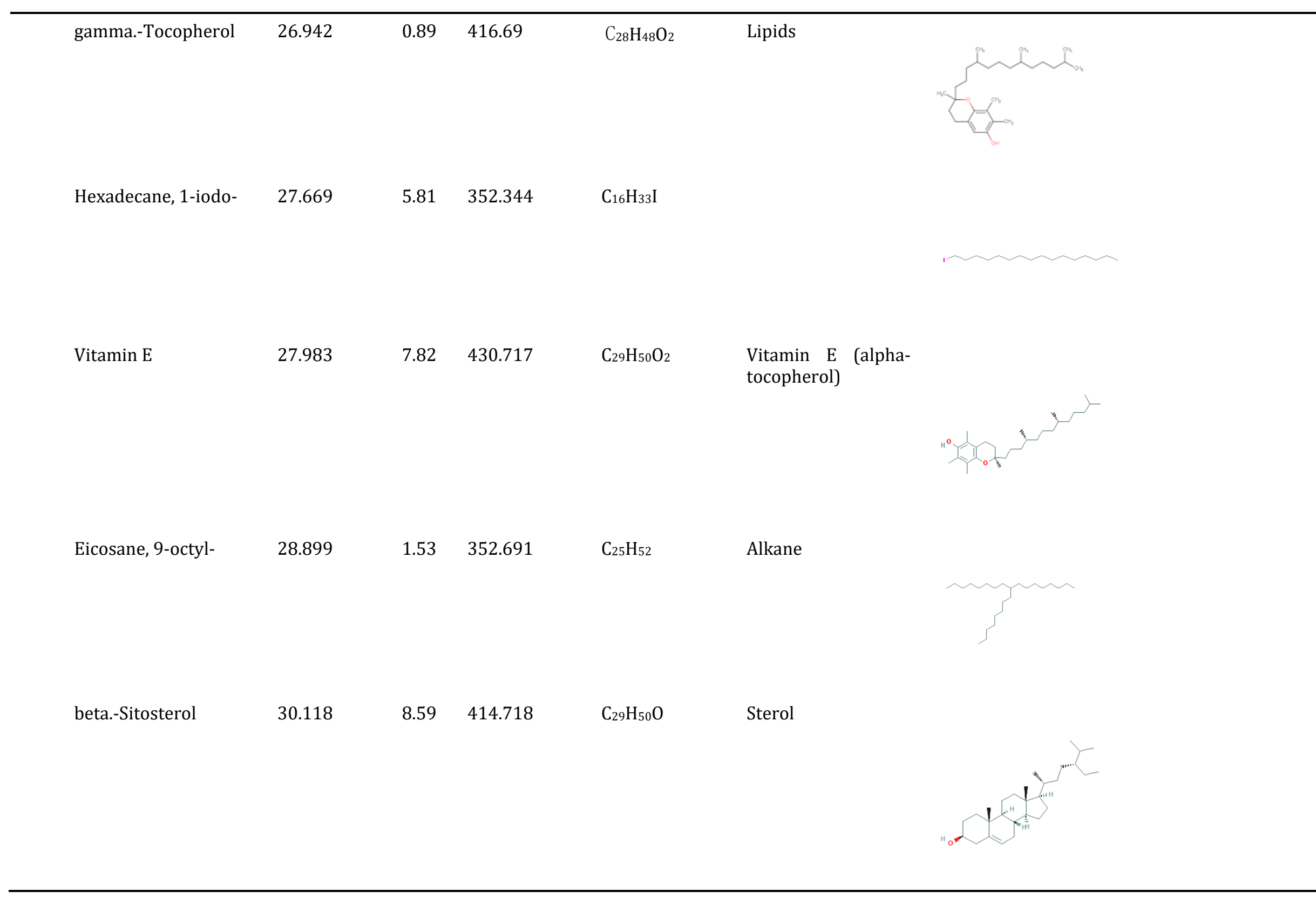




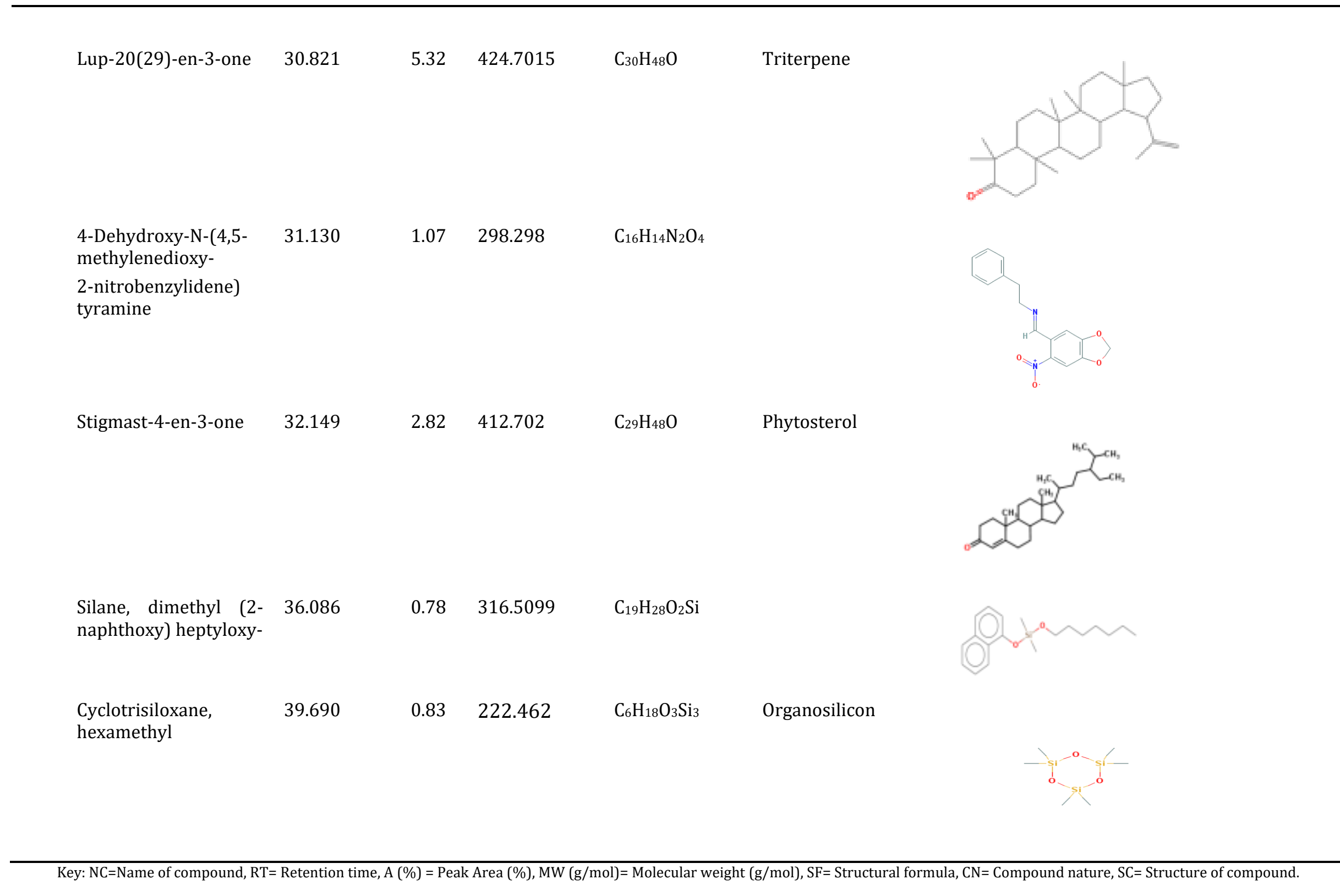




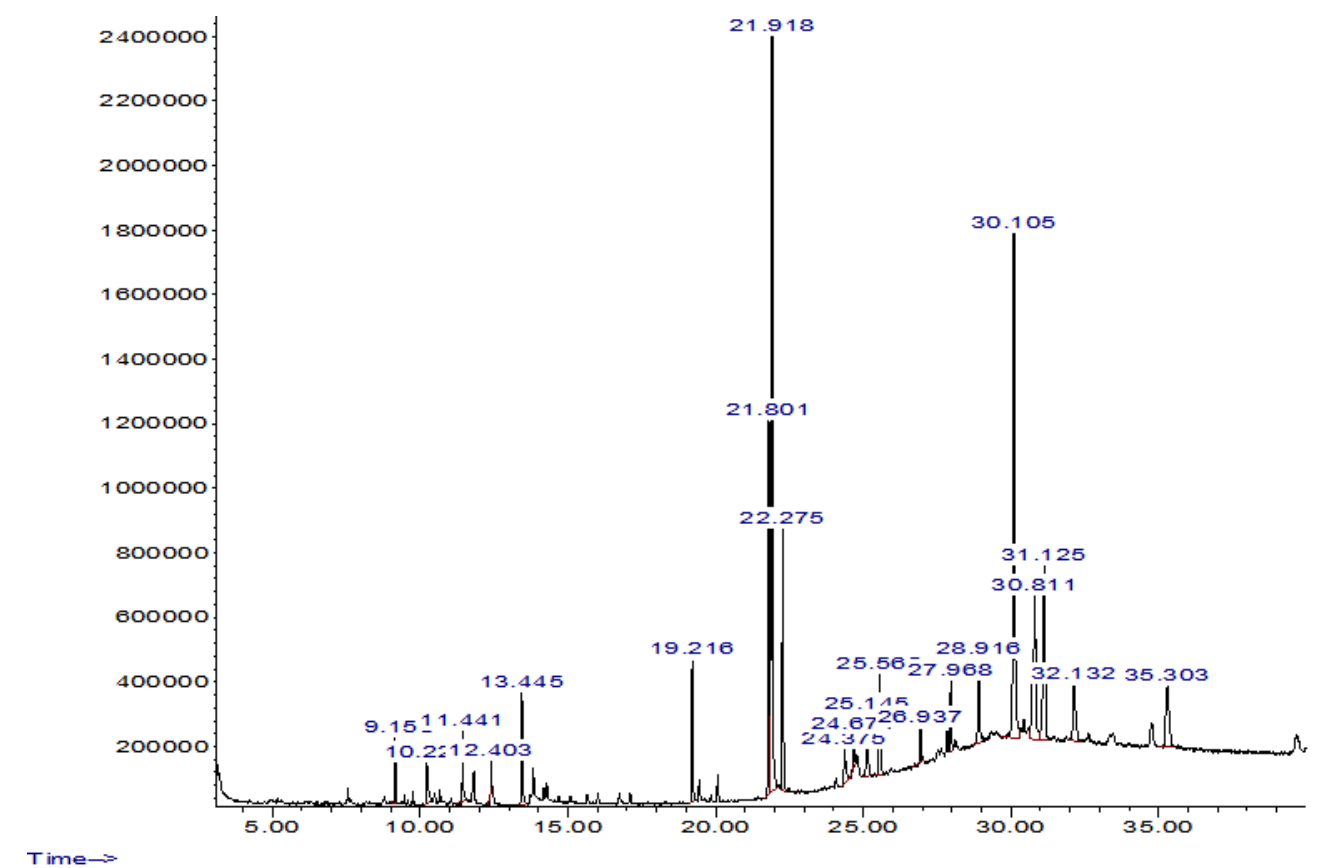

Figure 1 Chromatogram of Spondias mombin leaves' ethanol extract by GC-MS method.

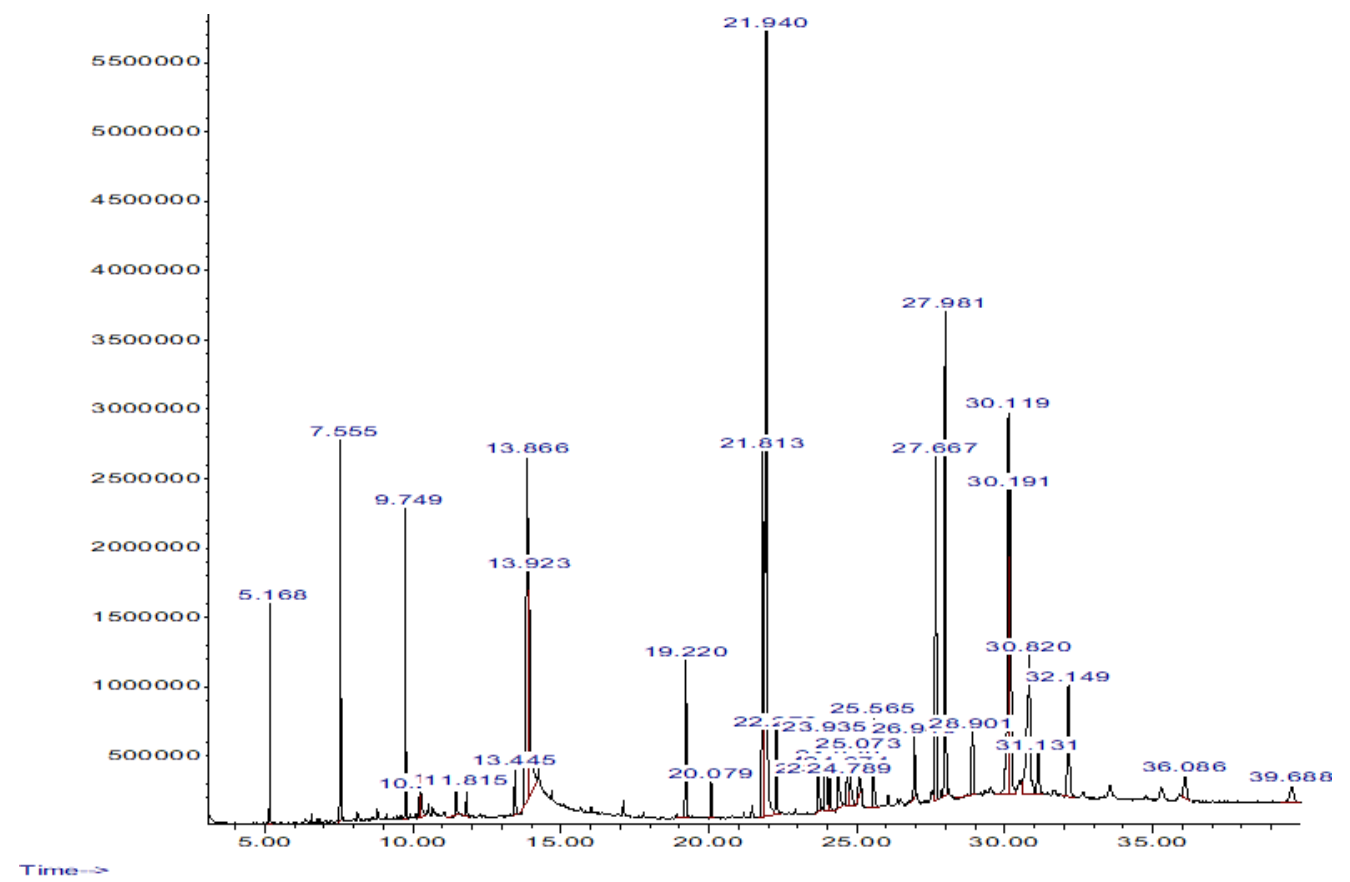

Figure 2 Chromatogram of Spondias mombin leaves' n-hexane extract by GC-MS method.

\section{Discussion}

The determination of phytochemicals in useful and regularly consumed plant products is significant. Thus, using gas chromatography and mass spectrometry (GC-MS) method, this study attempted to identify and quantify compounds present in the ethanol and n-hexane extracts of S. mombin leaves. Twenty five (25) compounds were identified in the ethanol extract of $S$. mombin leaves viz: 2(4H)-Benzofuranone (1.06\%), Bicyclo [3.1.1] heptane (1.41\%), nHexadecanoic acid (1.48\%), Hexadecanoic acid (0.88\%), 2-Hydroxy-1,8-naphthyridine $(0.37 \%)$, Phytol $(2.61 \%), 7,10$, 13-Hexadecatrienoic acid (1.03\%), Phenol, Diisooctyl phthalate (0.61\%), Phenol, 3-methyl- (8.74\%), Phenol, 2-methyl- 
(21.25\%), 3-pentadecyl- (5.93\%), Silane, diethyl (2-bromo-4-fluoroph enoxy) undecyloxy- (1.22\%), Silane, diethylpentadecyloxy (1-phenylpropoxy)- (1.80\%), Phenol, 4-(2-aminoethyl)- (1.00\%), 2H-1-Benzopyran-6-ol (2.46\%), gamma.-Tocopherol (0.76\%), Octasiloxane, 1, 1, 3, 3, 5, 5, 7, 7, 9, 9, 11, 11, 13, 13, 15, 15 hexadecamethyl (0.54\%), Vitamin E (1.62), 5-Methyl-2-phenylindolizine (1.93\%), gamma.-Sitosterol (16.16\%), Lup-20(29)-en-3-one (7.14\%), alpha-Amyrin (7.07\%), Stigmast-4-en-3-one (2.73\%), Octasiloxane, 1, 1, 3, 3, 5, 5, 7, 7, 9, 9, 11, 11, 13, 13, 15, 15-hexadecamethyl- (1.36\%), and 1-Dimethyl(phenyl)silyloxypentane (3.89\%). Spondias mombin n-hexane leaves extract also revealed twenty-nine compounds. The compounds were Decanoic acid, ethyl ester (1.75\%), Dodecanoic acid, ethyl ester (3.15\%), Tetradecanoic acid, ethyl ester (2.60\%), 1,2-Dihexylcyclopropene $(0.34 \%)$, Tetradecanal $(0.45 \%), \mathrm{n}$-Hexadecanoic acid $(0.27 \%)$, Pentafluoropropionic acid, pentadecyl ester $(0.34 \%)$, Phytol $(0.66 \%), 9,12$ Octadecadienoic acid (Z,Z) (8.93\%), Phenol, 3-pentadecyl- (2.31\%), Phthalic acid, di(oct-3-yl) ester (0.53\%), Phenol, 2methyl- (6.16\%), Phenol, 3-methyl- (17.80\%), 3-Amino-4-pyrazolecarbonitrile (1.37\%), Z,Z-10,12-Hexadecadien-1-ol acetate $(1.63 \%)$, Squalene $(0.60 \%), 1$-Pyrrolidinebutanoic acid $(0.80 \%)$, Eicosane $(0.58 \%), 2 \mathrm{H}-1$-Benzopyran-6-ol (1.50\%), gamma.-Tocopherol (0.89\%), Hexadecane, 1-iodo- (5.81\%), Vitamin E (7.82\%), Eicosane, 9-octyl- (1.53\%), beta.-Sitosterol (8.59\%), Lup-20(29)-en-3-one (5.32\%), 4-Dehydroxy-N-(4,5-methylenedioxy-2- nitrobenzylidene) tyramine (1.07\%), Stigmast-4-en-3-one (2.82\%), Silane, dimethyl (2-naphthoxy) heptyloxy- (0.78\%), and Cyclotrisiloxane, hexamethyl (0.83\%).

These compounds belong to different classes of compounds such as fat soluble vitamin E, steroids, fatty acids, terpenoids, terpenes and phenols. These bioactive chemicals produced by plants are used to support well-being and fight against contagions and many of them are sold as herbal medications or foods. Their usage has upsurge over the last era not only because of their low cost, ease of access, but also the belief that natural therapies have fewer harmful effects as related to synthetic analogues (Hadi et al., 2016).

Remarkably, both extracts evaluated had ten compounds in common. These are n-Hexadecanoic acid, Phytol, Phenol 3pentadecyl-, Phenol 3-methyl-, Phenol 2-methyl-, 2H-1-Benzopyran-6-ol, gamma-Tocopherol, Vitamin E, Lup-20(29)en-3-one, and Stigmast-4-en-3-one. These compounds identified have irresistible therapeutic usages. Phytol which was identified in the ethanol and n-hexane extracts of $S$. mombin leaves have been stated advantageous as an antibacterial agent active against Staphylococcus aureus, a precursor for Vitamins K and E, effective at different phases of arthritis (Inoue et al., 2005). It's antioxidant, anticancer and antinociceptive activities were reported by Ammal and Bai (2013). The presence of phytol in both extracts was in accordance with the report of Bekinbo et al. (2020), who studied methanol extract of S. mombin leaves. Ovuakporie-Uvo et al. (2018) also identified phytol in methanol extract of Desplatsia dewevrei leaves and fruits.

Vitamin E and gamma-Tocopherol identified in this study were also reported in the studies of Guedes et al. (2020) in $S$. mombin and S. tuberose. Recently, Abraham et al. (2019) revealed that vitamin E isoforms had anticancer activity with the exception of non-alpha-Tocopherol form. Gamma Tocopherols had been revealed to prevent the development of different kinds of tumor, including prostate tumor (Huang et al., 2014).

The identification of n-Hexadecanoic acids also known as palmitic acid in both extracts were reported to possess cyclooxygenase and antioxidants properties (Benkendorff et al., 2005; Suhaj, 2006). Perez-Pinzon and Lin (2013) stated that saturated fatty acids or polyunsaturated such as n-Hexadecanoic acids and $\alpha$-linolenic acid have ability of offering neuroprotection after ischemia. Agreeing to World Health Organization, the intake of n-Hexadecanoic acids upsurges the threat of developing cardiovascular illness (Uauy et al., 2009). Bekinbo et al. (2020) and Qureshi et al. (2020) also reported the presence of n-Hexadecanoic acids in methanol extract of S. mombin leaves and n-hexane extract of Kochia indica stem respectively. Elufioye and Berida (2018) also identified n-Hexadecanoic acids in n-hexane extract of the stem-bark and whole fruit of Spondias purpurea. n-Hexadecanoic acids were found earlier in Syzygium cumini and stated to have antifungal activities (Javaid et al., 2018). Similarly, Bhawanker et al. (2013) isolated n-Hexadecanoic acids from ethanol extract of Aloe vera and also recognized their antifungal and antibacterial activities against Candida albicans and Streptomyces greseus. n-Hexadecanoic acids, a significant antimicrobial compound identified in this study was also isolated from Brassica nigra oil and assessed against Aspergillus niger, Candida albicans, Staphylococcus aureus and Pseudomonas aeruginosa through cup plate agar diffusion assay by Abdel-Karim (2017).

Squalene, one of the compounds identified in n-hexane extract of $S$. mombin leaves in this study was also reported in the crude ethyl acetate root extract of $S$. mombin by Osuntokun et al. (2018). Guedes et al. (2020) also reported squalene in $\mathrm{n}$-hexane extract from $S$. tuberose and $S$. mombin leaves. It has been reported that squalene acts as a drug transporter by chemically linking with medicines to advance certain physicochemical properties. For instance, administration of squalene-doxorubicin nanohybrids caused higher decrease of pancreatic cancers when related with free doxorubicin (Wicki et al., 2015). Consequently, squalene based nanoparticles have been deliberated to be likely candidates for anticancer medications (Kotelevets et al., 2017; Saha et al., 2015). In the nutritious context, virgin olive oil is a vital basis of 
squalene (Beltrán et al., 2016). Intake of olive oil has been interrelated with lower risk of tumor growth in several cancer kinds (Newmark, 1999; Lozano-Grande et al., 2018). Kalvodona (2010) stated that squalene is not very vulnerable to peroxidation and seems to function in the skin as a quencher of daylight, guarding human skin surface from fat peroxidation owing to contact to UV and other sources of ionizing emission.

Also, 9, 12 Octadecadienoic acids identified in n-hexane extract of $S$. mombin leaves in this study had been determined in methanol extract of Nymphaea lotus and S. mombin to have antimicrobial activity (Odumosu et al., 2018). Qureshi et al. (2020) reported 9, 12 Octadecadienoic acids in n-hexane extract of Kochia indica stem. Likewise, Elufioye and Berida (2018) also reported 9, 12 Octadecadienoic acids in n-hexane extract of stem-bark and whole fruit of S. purpurea.

Alpha-amyrin identified in ethanol extract of S. mombin leaves in this study have been investigated in stem-bark of Ficus exasperate (Nogueira et al., 2019). Guedes et al. (2020) also reported alpha-amyrin in hexane extract of $S$. mombin and $S$. tuberose leaves. In numerous studies, alpha-amyrin has established an abundant pharmacological applicability in some diseases (Melo et al., 2010) that have a common feature in their development: inflammation as one of the key mechanisms involved in their origin (Ciccarelli et al., 2013).

Gamma-sitosterol present in ethanol extract of this study had also been reported in roots of Girardinia heterophylla (Tripathiathi et al., 2013). Qureshi et al. (2020) also reported the presence of gamma-sitosterol in n-hexane extract of Kochia indica stem. Gamma-sitosterol is a vital plant sterol and had been stated first time in Girardinia heterophylla (Tripathiathi et al., 2013). Gamma-sitosterol decreases the hyperglycemia in Steptozotocin-induced diabetic rats owing to upsurge insulin production and inhibition of glucogenesis (Tripathiathi et al., 2013). Sundarraj et al. (2012) also stated that gamma-sitosterol might affect the extent and activity of constituents of the extrinsic apoptotic pathway in human lung and breast adenocarcinoma cells. Ovuakporie-Uvo et al. (2018) also reported the presence of gammasitosterolin methanol extract of Desplatsia dewevrei fruit.

The beta-sitosterol identified in n-haxane extract of $S$. mombin leaves was also present in methanol extract of Desplatsia dewevrei leaves and fruit (Ovuakporie-Uvo et al., 2018). Qureshi et al. (2020) also reported beta-sitosterol in n-hexane extract of Kochia indica stem. Its biological activities had been reported by authors. Villasenor et al. (2002) reported beta-sitosterol as an anthelminthic component of Mentha cordifolia. They employed in vitro tests by Ascaris suum, which resulted in the similar performance of worms treated with beta-sitosterol together with the positive controls, antiox and combantrin. Rahuman et al. (2008) also reported the reasonable larvicidal activity of five herbal drugs including: Abutilon indicum, Solanum torvum, Jatropha gossypifolia, Euphorbia thymifolia and Aegle marmelos on the larvae of Culex quinquefasciatus. Remarkably, the key isolated compound from the petroleum ether extract of Abutilon indicum was recognized as beta-sitosterol, which introduces this natural compound as a unique mosquito larvicidal sterol.

\section{Conclusion}

In conclusion, the study had been able to determine the possible chemical constituents of the ethanol and n-hexane extracts of S. mombin leaves using GC-MS technique. A number of compounds identified were found in abundance in the extracts. However, the percentage proportion of these compounds differed in each extract. In view of this, the possible biological properties of these identified compounds suggested that $S$. mombin might possibly be potential therapeutic agents.

\section{Compliance with ethical standards}

\section{Acknowledgments}

The author recognized the technical skills of Mr. Isaac at the Central Laboratory of Federal University of Technology, Akure (FUTA).

\section{Disclosure of conflict of interest}

The author declared no conflict of interest. 


\section{References}

[1] Abdel-Karim M, Weam AMP, Yousif M and Inas OP. (2017). GC-MS Analysis and antimicrobial activity of sudanese Brassica nigra L. (Brassicaceae) fixed oil. Int. J. Sci. Eng. App. Sci., 3, 74-81.

[2] Abraham A, Kattoor AJ, Saldeen T and Mehta JL. (2019). Vitamin E and its anticancer effects. Critical reviews in food science and nutrition, 59(17), 2831-2838.

[3] Ammal RM and Bai GV. (2013). GC-MS Determination of bioactive constituents of Heliotropium indicum leaf. Journal of Medicinal Plants, 1(6), 30-33.

[4] Bawankar R, Deepti VC, Singh P, Subashkumar R, Vivekanandhan G and Babu S. (2013). Evaluation of bioactive potential of an Aloe vera sterol extract. Phytotherapy Research, 27(6), 864-868.

[5] Bekinbo MT, Amah-Tariah FS and Dapper DV. (2020). Comparative GC-MS determination of bioactive constituents of the methanolic extracts of Curcuma longa rhizome and Spondias mombin leaves. Journal of Medicinal Plants, 8(1), 01-06.

[6] Beltrán G, Bucheli, ME, Aguilera MP, Belaj A and Jimenez A. (2016). Squalene in virgin olive oil: screening of variability in olive cultivars. European Journal of Lipid Science and Technology, 118(8), 1250-1253.

[7] Benkendorff K, Davis AR, Rogers CN and Bremner JB. (2005). Free fatty acids and sterols in the benthic spawn of aquatic molluscs, and their associated antimicrobial properties. Journal of Experimental Marine Biology and Ecology, 316(1), 29-44.

[8] Ciccarelli F, Martinis MD and Ginaldi L. (2013). An update on autoinflammatory diseases. Curr. Med. Chem, 21, 261-269.

[9] Cowan MM. (1999). Plant products as antimicrobial agents. Clinical microbiology reviews, 12(4), 564-582.

[10] Dharmananda S. (2003). All nuts and the uses of tannins in Chinese medicine In., proceedings of institutes for traditional medicine port. 3938, land Oregon. African Journal Biotechnology, 1, 126-138.

[11] Ekor M. (2014). The growing use of herbal medicines: issues relating to adverse reactions and challenges in monitoring safety. Frontiers in pharmacology, 4, 177.

[12] Elufioye TO and Berida TI. (2018). GC-MS Analysis and Antioxidant Activity of Spondias purpurea L (Anacardiaceae). Pharmacognosy Journal, 10(5).

[13] Guedes JA, Alvesfilho E, Silva MF, Rodrigues TH, Ramires CM, Silva GD and Nascimento R. (2020). GC-MS-based metabolomic profiles combined with chemometric tools and cytotoxic activities of non-polar leaf extracts of Spondias mombin L. and Spondias tuberosa Arr. Cam. Embrapa Agroindústria TropicalArtigoemperiódicoindexado (ALICE).

[14] Huang H, He Y, Cui XX, Goodin S, Wang H, Du ZY and Yang CS. (2014). Potent inhibitory effect of $\delta$-tocopherol on prostate cancer cells cultured in vitro and grown as xenograft tumors in vivo. Journal of Agricultural and Food Chemistry, 62(44), 10752-10758.

[15] Igwe CU, Onwuliri VA, Osuagwu CG, Onyeze GOC and Ojiako OA. (2011). Biochemical and haematological studies on the ethanol leaf extract of Spondias mombin Linn. Biochem Anal Biochem, 1, 104.

[16] Inoue Y, Hada T, Shiraishi A, Hirose K, Hamashima H and Kobayashi S. (2005). Biphasic effects of geranylgeraniol, teprenone, and phytol on the growth of Staphylococcus aureus. Antimicrobial Agents and Chemotherapy, 49(5), 1770-1774.

[17] Kalvodova L. (2010). Squalene-based oil-in-water emulsion adjuvants perturb metabolism of neutral lipids and enhance lipid droplet formation. Biochemical and biophysical research communications, 393(3), 350-355.

[18] Kim JY, Suh S, In MK, Paeng KJ and Chung BC. (2005). Simultaneous determination of cannabidiol, cannabinol, and $\backslash \mathrm{gD}$ 9-tetrahydrocannabinol in human hair by gas chromatography-mass spectrometry in human hair by gas chromatography-mass spectrometry. Archives of pharmacal research, 28(9), 1086-1091.

[19] Kotelevets L, Chastre E, Caron J, Mougin J, Bastian G, Pineau A and Couvreur P. (2017). A squalene-based nanomedicine for oral treatment of colon cancer. Cancer research, 77(11), 2964-2975.

[20] Li H, Wang Z and Liu Y. (2003). Review in the studies on tannins activity of cancer prevention and anticancer. Zhongyaocai $=$ Zhongyaocai= Journal of Chinese Medicinal Materials, 26(6), 444-448. 
[21] Lozano-Grande MA, Gorinstein S, Espitia-Rangel, E, Dávila-Ortiz GandMartínez-Ayala AL. (2018). Plant sources, extraction methods, and uses of squalene. International Journal of Agronomy.

[22] Melo CM, Carvalho KMMB, de Sousa Neves JC, Morais TC, Rao VS, Santos FA and Chaves MH. (2010). $\alpha, \beta$-amyrin, a natural triterpenoid ameliorates L-arginine-induced acute pancreatitis in rats. World Journal of Gastroenterology: WJG, 16(34), 4272.

[23] Newman RA, Yang P, Pawlus AD and Block KI. (2008). Cardiac glycosides as novel cancer therapeutic agents. Molecular interventions, 8(1), 36.

[24] Newmark HL. (1999). Squalene, olive oil, and cancer risk: review and hypothesis. Annals of the New York Academy of Sciences, 889(1), 193-203.

[25] NIST. (2019). [National Institute of Standards and Technology] Chemistry Web Book, SRD 69. Search for species data by chemical name.

[26] Nogueira AO, Oliveira YIS, Adjafre BL, de Moraes MEA and Aragao GF. (2019). Pharmacological effects of the isomeric mixture of alpha and beta amyrin from Protium heptaphyllum: a literature review. Fundamental \& clinical pharmacology, 33(1), 4-12.

[27] Odumosu BT, Salawu OT, Oyeyemi I, Alabi OS, Rufai TR and Odunukan O. (2018). Bioactive constituents and antibacterial screening of two Nigerian plant extracts against selected clinical bacteria. Nigerian Journal of Pharmaceutical Research, 12(2), 127-137.

[28] Omoregie ES and Oikeh EI. (2015). Comparative studies on the phytochemical composition, phenolic content and antioxidant activities of methanol leaf extracts of Spondias mombin and Polyathia longifolia. Jordan Journal of Biological Sciences, 147(3427), 1-5.

[29] Osuntokun OT, Ige O0, Idowu TO and Gamberini MC. (2018). Bio-activity and Spectral Analysis of Gas Chromatography/Mass Spectroscopy (GCMS) Profile of Crude Spomdias mombin Extracts. SciFed Journal of Analytical Biochemistry, 1(2), 1-12.

[30] Ovuakporie-Uvo O, Idu M and Itemire AO. (2018). Phytochemistry, gas chromatography-mass spectrometry analysis and in vitro anti-bacterial activities of Desplatsia dewevrei (De Wild. \& T. Durand). Brazilian Journal of Biological Sciences, 5(10), 373-404.

[31] Perez-Pinzon M and Lin HW. (2013). The role of fatty acids in the regulation of cerebral vascular function and neuroprotection in ischemia. CNS NeurolDisord Targets (Formerly Curr Drug Targets-CNS NeurolDisord, 12(3), 316-24.

[32] Qureshi MZ, Javed S, Javaid A and Al-Taie AH. (2020). Identification of antimicrobial compounds from n-hexane stem extract of Kochia indica by GC-MS analysis. MYCOPATH, 16(2).

[33] Rahuman AA, Gopalakrishnan G, Venkatesan P and Geetha K. (2008). Isolation and identification of mosquito larvicidal compound from Abutilon indicum (Linn.) Sweet. Parasitology research, 102(5), 981-988.

[34] Saha D, Testard F, Grillo I, Zouhiri F, Desmaele D, Radulescu A and Spalla O. (2015). The role of solvent swelling in the self-assembly of squalene based nanomedicines. Soft matter, 11(21), 4173-4179.

[35] Sathiyabalan G, PackiaLincy M, Muthukumarasamy S and Mohan VR. (2014). GC-MS analysis of bioactive components of Petiveria alliacea L. whole plant (Phytolaccaceae). International Journal of Pharma Research and Health Sciences, 2(5), 387-392.

[36] Shaarawy SM, Tohamy AA, Elgendy SM, Elmageed ZYA, Bahnasy A, Mohamed MS and Matrougui K. (2009). Protective effects of garlic and silymarin on NDEA-induced rats hepatotoxicity. International journal of biological sciences, 5(6), 549.

[37] Shah I, Al-Dabbagh B, Salem AE, Hamid SA, Muhammad N and Naughton DP. (2019). A review of bioanalytical techniques for evaluation of cannabis (Marijuana, weed, Hashish) in human hair. BMC chemistry, $13(1), 106$.

[38] Suhaj M. (2006). Spice antioxidants isolation and their antiradical activity: a review. Journal of food composition and analysis, 19(6-7), 531-537.

[39] Sundarraj S, Thangam R, Sreevani V, Kaveri K, Gunasekaran P, Achiraman SandKannan S. (2012). $\gamma$-Sitosterol from Acacia nilotica L. induces G2/M cell cycle arrest and apoptosis through c-Myc suppression in MCF-7 and A549 cells. Journal of ethnopharmacology, 141(3), 803-809. 
[40] Tripathiathi N, Kumar S, Singh R, Singh CJ, Singh P and Varshney VK. (2013). Isolation and Identification of $\gamma$ sitosterol by GC-MS from Roots of Girardinia heterophylla. Oriental Journal of Chemistry, 29(2), 705.

[41] Uauy R, Aro A, Clarke R, L'abbé MR, Mozaffarian D, Skeaff CM and Tavella M. (2009). WHO Scientific Update on trans fatty acids: summary and conclusions. European Journal of Clinical Nutrition, 63(2), S68-S75.

[42] Villaseñor IM, Angelada J, Canlas AP and Echegoyen D. (2002). Bioactivity studies on $\beta$-sitosterol and its glucoside. Phytotherapy Research: An International Journal Devoted to Pharmacological and Toxicological Evaluation of Natural Product Derivatives, 16(5), 417-421.

[43] Wicki A, Witzigmann D, Balasubramanian V and Huwyler J. (2015). Nanomedicine in cancer therapy: challenges, opportunities, and clinical applications. Journal of controlled release, 200, 138-157.

\section{How to cite this article}

Akanji OC. (2020). Determination of bioactive constituents of Spondias mombin leaves by GC-MS analysis. World Journal of Advanced Research and Reviews, 6(3), 149-165. 